\title{
GÉNESIS Y EVOLUCIÓN DE UN ARRABAL SEVILLANO: LA CESTERÍA
}

\section{GENESIS AND EVOLUTION OF THE SEVILLIAN SUBURB OF LA CESTERÍA}

\author{
por \\ DANIEL JIMÉNEZ MAQUEDA; \\ GREGORIO MOSULÉN FERNÁNDEZ; \\ OLGA SÁNCHEZ LIRANZO; \\ LAURA JIMÉNEZ MAQUEDA y \\ ROSARIO RODRÍGUEZ CORDONES ${ }^{1}$
}

RESUMEN En el presente artículo pretendemos reconstruir la génesis y evolución del arrabal sevillano de la Cestería, emplazado en las proximidades de la Puerta de Triana (fig. 1), desde su fundación en los siglos XIV-XV hasta la actualidad. Para ello utilizaremos los datos que proporcionaron las intervenciones arqueológicas de urgencia en Reyes Católicos $\mathrm{n}^{\circ} 3 / \mathrm{Almansa}^{\circ} 6$ y Almansa nº 5 (Jiménez Maqueda y Mosulén 1997 y 1998).

ABSTRACT In this article we try to rebuild the genesis and evolution of the Sevillian suburb, the Cestería, settled near the Triana Gate (fig. 1), since its foundation in the centuries XIV-XV. To do so, we will use the data provided by the urgent archaeological interventions in Reyes Católicos $\mathbf{n}^{\circ}$ 3/Almansa $n^{\circ} 6$ y Almansa n 5 (Jiménez Maqueda and Mosulén 1997 and 1998).

\section{INTRODUCCIÓN.}

Las intervenciones arqueológicas de urgencia en las calles Reyes Católicos $n^{\circ} 3 / \mathrm{Almansa} \mathrm{n}^{\circ} 6(\mathrm{Rc} 3 / \mathrm{Al} 6)$ y Almansa $\mathrm{n}^{\circ} 5$ ( $\mathrm{Al}$ 5) (fig. 2) tuvieron lugar en octubre y noviembre de 1997 y en julio de 1998 respectivamente.

En relación al proceso de excavación, en $\mathrm{RC} 3 / \mathrm{Al} 6$ se realizaron dos sondeos estratigráficos, uno de $6 \times 6$ m. (U.I. 1) y otro de $5 \times 5$ m. (U.I. 2), mientras que en Al 5 se practicó un sondeo de $5 \times 5$ m. Señalar que en ninguno de los tres se agotó el registro estratigráfico debido a la aparición del nivel freático.

1. Los autores desean agradecer la ayuda que les han prestado las siguientes personas: Fernando Amores en la corrección del texto, Pedro Pérez Quesada en la confección de la planimetría y Pina López en el estudio del material cerámico. Asimismo, debemos agradecer a don José Reyes y don Jesús Ortiz todas las facilidades que nos proporcionaron en la realización de ambas intervenciones arqueológicas de urgencia. 


\section{EL ORIGEN DEL ARRABAL: LA BAJA EDAD MEDIA.}

Durante la Antigüedad el emplazamiento del futuro arrabal de la Cestería se localiza a considerable distancia del recinto de la Hispalis romana, cuyo límite occidental no debió ir más allá de la calle Sierpes y la avenida de la Constitución (Blanco 1972: 16 y 1979: 128; Collantes de Terán Delorme 1977: 73; y Campos 1993: 188-190). En este momento, el sector se definiría por su carácter inhóspito, formando parte de una zona pantanosa y de constante inundación.

Este mismo carácter debió mantenerse durante la alta y plena Edad Media, puesto que el perímetro de la Isbiliya emiral y taifa coincidiría sustancialmente con el de la Hispalis romana (Jiménez Martín 1981: 16 y Valencia 1988: 140-144), de manera que no sería hasta la primera mitad del siglo XII, en la que los Almorávides erigieron el recinto amurallado derribado en el XIX, cuando el solar quedaría muy próximo a la ciudad, cuya cerca correría por la medianera de las calles Zaragoza y Santas Patronas (Valor 1991: 128 ss.), inmediato a la Puerta de Triana, aunque no hemos localizado edificaciones de los siglos XII y XIII.

Por el contrario, hasta el siglo XIV hemos excavado tan solo niveles de inundación, como las UUEE 87 y 88 de la U.I. 1 de RC 3/Al 6, las UUEE 405, 407 y 415 de la U.I. 2 y la UE 53 de Al 5, seguidas y/o precedidas por paquetes de relleno a base de cascotes, fragmentos de tejas, guijarros de dimensiones variables, ostiones y abundante material cerámico vidriado y bizcochado, aunque muy fragmentado, tales como las UUEE 409, 416 y 417 de la U.I. 2 de RC 3/Al 6 y las UUEE 52 y 54 de Al 5 (figs. 9-11).

Así pues, la visión que nos proporciona la arqueología es la de un espacio abierto, sometido a los aportes sedimentarios del Guadalquivir, los cuales son siempre seguidos por operaciones de subida de la cota de uso mediante sucesivos vertidos de escombros, relacionados con la conversión del Arenal en un espacio cualificado, fruto de su emplazamiento junto al puerto de la ciudad y al pie de la cerca beréber.

Por lo tanto, los resultados de las dos excavaciones ponen de manifiesto la ausencia de construcciones anteriores al siglo XIV, lo que confirmaría la información proporcionada por los documentos del Archivo Municipal (Collantes de Terán Sánchez 1977: 97-99) y la historiografía sevillana (Ortiz de Zúñiga 1677: 15 y González de León 1839: 550) acerca de la urbanización del arrabal de la Cestería en la baja Edad Media.

En este sentido, la evidencia edilicia más antigua documentada en ambas excavaciones la constituye, en la U.I. 2 de RC 3/Al 6 (fig. 3), un muro (UE 360/375) de $60 \mathrm{~cm}$. de anchura, fábrica de ladrillos del formato $30 \times 14 \times 5 \mathrm{~cm}$. dispuestos en hiladas alternas de soga y tizón -si bien en el interior de las primeras era frecuente el empleo de cascotes y guijarros- $y$ tomados con un mortero consistente en llagas amplias, y cimentación diferenciada formada por una zapata (UE 363/425) de tan solo dos hiladas de ladrillos. A este muro se asociaban los restos de dos pavimentos: uno de argamasa de color anaranjado (UE 413/450) y otro (UE 445) de fragmentos de ladrillos y factura muy tosca.

En cuanto a su acotación cronológica, los argumentos que nos permiten fechar en el siglo XIV el origen del arrabal de la Cestería se refieren tanto a la tipología del muro UE 360, como al análisis detenido del material cerámico asociado ${ }^{2}$.

Por lo que a $\mathrm{Al} 5$ respecta, el primer hito edilicio lo constituyen dos muros a escuadra (UUEE 30 y 32 ) realizados con una fábrica de grandes mampuestos careados, ladrillos del formato $30 \times 14 \times 5 \mathrm{~cm}$. dispuestos en hiladas alternas de soga y tizón -algunos aislados de canto-y cascotes en su interior, con una cimentación diferenciada constituida por una zapata de sillares alcorizos y tejas.

2. Así, bajo el pavimento UE 440 obtuvimos un fragmento de plato cónico (ROD 97/32 163) (fig. 12) con anillo de repié, paredes rectas divergentes, labio resaltado, reverso sin cubierta y anverso blanco decorado en el centro y el borde con un verde de óxido de cobre a pincel que se fecha en el siglo XIV (Pleguezuelo y Lafuente 1995: 225-226 y Lafuente 1997: fig. 55.7), mientras que el muro UE 360 se encontraba, tal y como veremos más adelante, amortizado por un conjunto cerámico característico del fines del XV e inicios del XVI. 
Asociados a ambos muros no se localizó resto alguno de pavimento, aunque, coincidiendo con la cota inferior del enfoscado del muro UE 30, se documentó un nivel de argamasa con abundante cal (UE 47) que constituía un indicio de su existencia, lo que nos permite situar su primitiva cota de uso hacia 4'50/ 4'60 m. s.n.m. (fig. 11).

En lo que a sus bases cronológicas se refiere, la proporcionan la tipología de los muros así como el material cerámico de las UUEE 52, 49 y 44, que la situarían en la segunda mitad del siglo XV (fig. 13), como pondrían de manifiesto diversos fragmentos procedentes de la localidad levantina de Manises ${ }^{3}$, otros tantos (191) de la serie denominada azul y morada (Pleguezuelo et alii 1997: 132), uno de plato y otro de fuente melados con decoración de manganeso bajo cubierta en el anverso $(185 \text { y } 231)^{4}$ y un plato de la denominada vajilla verde.

\section{LA CONSOLIDACIÓN: LOS SIGLOS XVI-XVIII.}

Los siglos correspondientes a la Edad Moderna suponen la definitiva consolidación del arrabal de la Cestería, pudiéndose señalar tres grandes episodios constructivos relacionados con hitos de la historia de la ciudad de Sevilla:

a) El de la primera mitad del siglo XVI, cuando el establecimiento del monopolio comercial con las Indias aumentó la importancia del Arenal y por ello de los arrabales de la Cestería y la Carretería, profundamente vinculados al tráfico portuario.

b) El de comienzos del XVII, asociado al traslado y nueva construcción de la Puerta de Triana, que libera los terrenos ocupados por la alcantarilla que conducía a la antigua puerta.

c) Un tercero que se fecha a finales del siglo XVII o principios del XVIII y que supone una manifiesta pérdida de entidad de las edificaciones, en un momento en que Sevilla experimenta una profunda crisis, ocasionada por la peste de 1649-1652 y la pérdida del monopolio comercial con América, que debió incidir especialmente en un arrabal portuario como la Cestería.

En este sentido, en la Vista de Sevilla desde Triana de Wyngaerde (lám. III), en el óleo anónimo del Museo de América de Madrid, de fines del XVI, en el también anónimo del Ayuntamiento sevillano, de 1726, y en el Plano del asistente Olavide (lám. IV), el arrabal de la Cestería aparece ya configurado.

\subsection{LA PRIMERA MITAD DEL SIGLO XVI.}

Sin duda, el siglo XVI se manifiesta con singular entidad en RC 3/Al 6, puesto que a su primera mitad corresponden dos expedientes constructivos de considerable envergadura.

3. En concreto, nos referimos a una escudilla (ROD 98/13233) (fig. 13) decorada en el anverso con las denominadas "palmas abiertas" o "palmitos" dentro de líneas envolventes y círculos azules y dorados, y en el reverso con circunferencias concéntricas enmarcando una faja con trazos paralelos oblicuos, motivo éste frecuente desde el último tercio del siglo XIV hasta fines de la cuarta década del XV (Llubia 1967: 160, lám. 251 y Martínez 1982: 135, fig. 108); otra (234) (fig. 13) dotada de repié anular, decorada en su anverso con "trazos rectos con una espiral" en azul cobalto y que se fecha en el primer tercio del XV (Martínez 1982: 133, dib. 8); y una tercera de la serie blanca y azul (229) (fig. 13) que se fecha en los siglos XIX-XV. Asimismo, cabe mencionar un fragmento de cuenco y otro de plato con sus características pastas rosáceo-anaranjadas.

4. Su producción, pese a iniciarse en la segunda mitad del siglo XIV y alcanzar incluso el XVI, sitúa su mayor desarrollo en el XV (Lafuente 1997: 125, fig. 52). 
En la U.I. 1 una estructura abovedada (UE 100) (lám. I) realizada con ladrillos tomados con un mortero de enorme consistencia, unas dimensiones máximas documentadas de 6.01 m. de anchura y un arco de medio punto de 2'55 m. de luz, en cuya rosca se disponían los ladrillos alternando uno completo con fragmentos de dos y en una de cuyas enjutas entestaba un muro (UE 109) de tapial que formaba un ángulo de $90^{\circ}$ con otro (UE 105), el cual, a su vez, formaba con un tercero (UE 106) otro ángulo de $90^{\circ}$ (fig. 4).

En virtud de su emplazamiento, inmediato a la primitiva Puerta de Triana, localizada al final de la actual calle Moratín, hemos interpretado esta estructura como una de las alcantarillas de la calzada que conducía desde el puente de barcas a la puerta mencionada, y hacia ella debían conducir el agua los muros de tapial documentados.

En relación a este punto, en la descripción que Mal Lara hace de la entrada de Felipe II en nuestra ciudad en 1570, se expresa en los siguientes términos: “(...) hasta la puerta de Triana, passo los arcos de la Puente, que desde la ciudad hasta la de madera tiene ciertos ojos de arcos, o alcantarillas, pordonde se desagua el río, quando en sus auenidas se embrauesce (...)" (Mal Lara, 1570: 48).

Ahora bien, resulta complicado atribuir una cronología precisa a nuestra alcantarilla, aunque para ello dispongamos de algunos elementos ${ }^{5}$ :

- Su construcción cortó a las UUEE 88 y 89 , en las que figuran algunos fragmentos cerámicos que pueden corresponder a los siglos XIII y XIV, lo que supone una fecha postquem.

- Se encontraba sellada por un muro de ladrillos y colmatada en su mayor parte por un paquete de limos y un relleno de escombros, con restos de la propia estructura, en el que obtuvimos un fragmento de azulejo (79) (fig. 12) por tabla de arista con un tema de bolas gallonadas y motivos vegetales flordeliselados en tonos negro, azul, melado y verde sobre fondo blanco que se fecha en el siglo XVI (Pleguezuelo 1989: 140, $\left.n^{\circ} 139\right)$.

— En 1417 se procedió a derribar la disposición acodada de la puerta islámica (Collantes de Terán Delorme 1972: 563-564, doc. 129), operación que quizá fuese acompañada de un adecentamiento de la calzada que le daba acceso y que pudo haber incluido la construcción de la alcantarilla excavada.

- Sabemos que en 1592 se concluyó la Puerta Nueva de Triana, en la confluencia de las calles Reyes Católicos, San Pablo, Zaragoza y Gravina, y se procedió a derribar la antigua (Albardonedo 1992), con lo que la alcantarilla debió perder su utilidad.

Por lo tanto, creemos que debió erigirse en algún momento comprendido entre mediados del siglo $\mathrm{XV}$ y la primera mitad del XVI, fecha en la que parece encajar la disposición de los ladrillos de la rosca de su arco.

En cuanto a la U.I. 2 de RC 3/Al 6 (fig. 5), se evidencia una vasta operación edilicia (lám. II) que se manifiesta en la construcción de una vivienda que reaprovechaba parcialmente las estructuras del siglo XIV y de la que cabe destacar como elementos más significativos un pavimento (UE 370/372) de losas bícromas del formato $30 \times 14 ' 5 \times 5 \mathrm{~cm}$. dispuestas a la palma, aunque se adaptaba a los muros mediante una orla perimetral, y varios suelos de ladrillo de canto (UUEE 350,371,373,374), cuya conexión con el primero nos impidió determinar la cimentación de la edificación decimonónica.

Estos restos corresponderían a un ámbito residencial del cual nos es posible sugerir su condición de espacio a cielo abierto integrado por un patio de extraordinaria factura y dotado de un elemento ornamental, identificable con un estanque o pilón (UUEE 390 y 395), flanqueado por un área de servicio anexa.

5. A modo de hipótesis, podría sugerirse que nuestra alcantarilla sustituyó a una de las que las fuentes islámicas nos informan que mandó construir Abu Yaqub Yusuf tras la inundación del año 564 H/1 168-1169: "Labró la alcazaba interior y exterior en las afueras de la puerta de al-Kuhl y los palacios nobles fuera de la puerta de Yahwar y los puentes alrededor de la ciudad por todas partes" (Ibn Sahib al-Sala: 1969, 65). 
Por otra parte, la cronología de este edifico viene determinada por la propia tipología del pavimento de losas así como por un material cerámico homogéneo que nos retrotrae a fines del siglo XV y comienzos del XVI ${ }^{6}$ (fig. 12).

\subsection{EL PRIMER TERCIO DEL SIGLO XVII:}

Constituye este el tercer hito constructivo documentado en ambas excavaciones, integrado por un proceso de sustitución inmobiliaria generalizado que en RC 3/Al 6 anula por completo al edificio del siglo XVI, así como la alcantarilla, aunque en $\mathrm{Al} 5$ se limita a reaprovechar la construcción del XV.

De este modo, en la U.I. 1 de RC 3/Al 6 (fig. 6) se documentó una edificación de carácter doméstico de la que identificamos diversas dependencias, tales como una estancia dotada de un pavimento (UE 35) de losas del formato $30 \times 14 \times 5 \mathrm{~cm}$. dispuestas a la palma y en la que se había excavado un pozo (UE 6), así como un patio de ladrillos de canto (UUEE 71 y 74) y guijarros (UE 72) al que daba acceso un umbral (UE 73).

En la U.I. 2 se amortizó el edifico de la primera mitad del siglo XVI mediante un relleno (UE 365) que contenía una cerámica muy homogénea ${ }^{7}$ (fig. 12) y un pavimento de ladrillos de canto (UE 309), sin duda perteneciente a la misma edificación documentada en la U.I. 1.

En cuanto a Al 5 (fig. 7) a esta cronología ha de adscribirse, tal y como ya hemos indicado, un reaprovechamiento del edificio del $\mathrm{XV}$, subiendo para ello la cota de uso mediante dos pavimentos de guijarros y ladrillos (UUEE $35 / 36$ y 45 ).

\subsection{LOS SIGLOS XVII Y XVIII:}

Como ya hemos señalado con anterioridad, en algún momento de fines del siglo XVII o el XVIII un nuevo proceso de sustitución inmobiliaria se detecta en ambas excavaciones ${ }^{8}$, con un evidente descenso en la factura y calidad de los expedientes constructivos.

Además, tanto en RC 3/Al 6 como en Al 5 estas estructuras se encontraban profundamente afectadas en planta y alzado por el sistema de saneamiento y la cimentación de las edificaciones de los siglos XIX y XX respectivamente.

Así, en la U.I. 1 de RC 3/Al 6 se limitaban a una serie de pavimentos de ladrillo de canto inconexos, con la particularidad de que se mantuvo en funcionamiento la estancia del pozo, a la que se accedería ahora mediante una escalera, mientras que en la U.I. 2 (fig. 8) se individualizó un pasillo (UUEE 330, 334 y 359) con estancias a un lado (UE 333) y al otro (UUEE 345 y 347).

6. En él cabe destacar una escudilla (126) (fig. 12) de la serie blanca lisa con la base cóncava, carena marcada y apéndices que se fecha en el siglo XV (Pleguezuelo y Lafuente 1995: fig. 18.8.1), otra vidriada y una tercera de la serie blanca lisa con decoración blanca y verde que se fecha en el XV (Pleguezuelo et alii 1997: 133, fig. 60.4); la base de una jarra plana y fondo marcado aunque sin constituir un pie anular; el fragmento de un plato (127) (fig. 12) decorado en el anverso con rosas de seis pétalos en azul sobre fondo blanco e interpretada como copia del siglo XV de la azul contemporánea de Manises (Pleguezuelo y Lafuente 1995: 228, fig. 18.9); otro melado con decoración de manganeso bajo cubierta en el anverso (132) (fig. 12); y el de un azulejo por tabla de arista con tonos negro, verde y melado.

7. Varios fragmentos de platos de la serie Sevilla azul sobre azul, de jarra de la serie azul figurativa que se fecha entre 1550 y 1630 (Deagan 1987:61), de jarra de la serie azul moteado cuya cronología corresponde al siglo XVII (Pleguezuelo et alii 1997: 138 , fig. 64), de la serie azul lineal de paralelas en su variante figurada (107) (fig. 12) y de lebrillo vidriado en verde.

8. En relación a este punto, en la excavación de urgencia practicada en las calles Pastor y Landero 31/Galera 26-28 se constató que el inmueble derribado conservaba aún elementos estructurales de la primitiva vivienda, cuya cronología se situaba a lo largo de la segunda mitad del siglo XVI, documentándose además dos reformas posteriores a lo largo de los siglos XVII y XVIII (Quirós 1999: 519). 
Por lo que a $\mathrm{Al} 5$ se refiere (fig. 11), sólo fue posible documentar varios pavimentos de losas superpuestos (UUEE 38, 37 y 28), lo que indicaría la prolongada vida de la edificación a la que pertenecían, que debió llegar hasta mediados del siglo XX.

En cuanto a la cronología de este episodio constructivo, la escasa superficie conservada en ambas excavaciones dificulta determinarla con exactitud, pues solo resulta obvio que en virtud de sus relaciones estratigráficas sería posterior a la de principios del XVII y anterior a la del siglo XIX en RC 3/Al 6 y a la del XX en $\mathrm{Al} 5$.

Tan sólo en esta última contamos con argumentos más precisos, pues bajo el pavimento UE 38 se detectó un estrato (UE 42) que contenía abundante material cerámico fechable a lo largo del XVII (fig. 14) y en el que pueden mencionarse varios fragmentos de platos de la serie azul sobre blanco ${ }^{9}$, otros tantos de jarra de la serie azul moteada (145) e incluso uno de imitación local de las cerámicas de Talavera de la Reina (146), puesto que carece del negro de manganeso que sirve allí para trazar el dibujo (Pleguezuelo et alii 1997: 142).

\section{LA IMAGEN ACTUAL: LOS SIGLOS XIX Y XX.}

A mediados del siglo XIX, y como consecuencia de la construcción del Puente de Isabel II y el establecimiento de la terminal del ferrocarril Córdoba-Sevilla, el sector adquirió una gran importancia, fenómeno que se plasmaría en la urbanización de las afueras de la Puerta de Triana y la alineación de la Cestería según proyecto de Balbino Marrón de 1859 (Suárez 1986: 194-197 y Marín 1980: 40).

Dicho proyecto significó el trazado de tres nuevas manzanas que habrían de dar a la Cestería el aspecto que presenta hoy en día: una rectangular, que suponía la creación de la calle Reyes Católicos, destinada a comunicar la Puerta de Triana con el puente, y la formación del segundo tramo de la calle Almansa; otra triangular, con la que se atirantaba la calle Arenal; y una tercera agregada al edificio de la Cárcel del Pópulo por el lado que miraba al Guadalquivir, responsable de la creación de la calle Genil.

En las dos U.I. de RC 3/Al 6 este proceso de alineación se identificó con el arrasamiento de las estructuras del siglo XVIII, el vertido de potentes rellenos de escombros (UUEE 1 y 300) en los que figuraba abundante material cerámico del XIX ${ }^{10}$ (fig. 12) y la construcción de un edificio, que presenta ya los límites parcelarios actuales, del que excavamos su sistema de saneamiento (UE 5) y la cimentación de una de sus crujías (UUEE 307 y 308), de una factura extraordinaria.

Ahora bien, en Al 5 no se detectaron huellas de esta intensa actividad urbanizadora, en la medida en que no sería hasta mediados del presente siglo cuando se construiría la edificación que sustituye a la de los siglos XVII-XVIII.

Se configura así la distinción fundamental que caracteriza a la Cestería, ya convertida en barrio con el derribo de la Puerta de Triana en 1869: un carácter popular para el conjunto del mismo, marginado de las grandes operaciones urbanísticas de la segunda mitad del siglo XIX, y del que serían claros ejemplos algunas casas de la calle Galera, como los números 4 y 20 , y una fachada a Reyes Católicos, convertida en el eje natural de penetración oeste-este de la ciudad, ocupada por las viviendas de la burguesía, entre las que, además de la excavada, podrían señalarse las de los números 11, 13, 21 y 23.

9. Como uno de ala diferenciada (Pleguezuelo et alii 1997: 142), otro con motivos vegetales que alternan con líneas concéntricas (154) (fig. 14) y un tercero de importación lisboeta y decorado con motivos encuadrados en cartelas (155) (fig. 14).

10. Como fragmentos más significativos señalar los de lebrillos polícromos (Huarte y Somé 1995: 234, fig. 11.2), uno de bacín (36) (fig. 12) del tipo denominado por Goggin (1968: 201) Blue Green Basin en su variedad "Triana Polícromo" (Deagan 1987: 93-95; Amores y Chisvert 1993: 288, núms. 122 y 124; y Huarte y Somé 1995: 234, fig. 11.1) y un tercero de loza inglesa de Davenport con decoración estampada (32) (fig. 12). 


\section{CONCLUSIONES.}

Como punto de partida de estas líneas, digamos que no puede realizarse una reconstrucción de la génesis y la evolución del arrabal de la Cestería sin tener presente en todo momento que este forma parte y se halla estrechamente vinculado a una porción de la ribera fluvial del Guadalquivir que se conocerá desde el siglo XIII como Arenal.

Hecha esta precisión, hay que remontar su génesis a la ampliación hacia el oeste del recinto amurallado de la Isbiliya almorávide durante la tercera y cuarta décadas del siglo XII, pues sólo entonces, y al amparo del sistema defensivo integrado por las torres del Oro y de la Almenilla, ya en el primer cuarto del XIII, este espacio adquiere las condiciones necesarias para el establecimiento de actividades vinculadas al tráfico portuario.

Esta cualificación funcional habría de intensificarse con la reconquista castellana, como pondrían de manifiesto la erección de las Atarazanas en su emplazamiento actual por Alfonso X en 1252, hasta tal punto de que será a lo largo del siglo XIV cuando se conformen los arrabales de la Cestería y la Carretería, ninguno de los cuales puede interpretarse como el resultado del crecimiento demográfico o la falta de espacio intramuros, puesto que desde mediados del siglo XIII hasta inicios del XV Sevilla experimenta una importante contracción en el número de sus habitantes.

Pese a todo, no resulta fácil ofrecer una aproximación de carácter funcional de las primeras evidencias de urbanización de la Cestería, en la medida en que no es mucho lo que de ellas nos han permitido recuperar las sucesivas edificaciones. En este sentido, ante la consistencia de los muros documentados en Al 5, quizás nos encontremos frente a una dependencia portuaria, como un almacén, si bien nada puede afirmarse en relación a $\mathrm{RC} 3 / \mathrm{Al} 6$.

Estas dificultades de interpretación desaparecen desde el siglo XVI, pues a partir de ahora todos los restos excavados corresponden a edificaciones de carácter residencial, lo cual indica que esta función se ha hecho preponderante, con la excepción de la alcantarilla que permitía el acceso a la Puerta Antigua de Triana, elemento éste que en nuestra opinión supone el hallazgo más destacado proporcionado por ambas excavaciones.

En efecto, en RC 3/Al 6 hemos tenido la fortuna de documentar arqueológicamente una operación que supuso el traslado del emplazamiento de la Puerta de Triana y que permitió incorporar al entramado urbano del arrabal los terrenos ocupados por la mencionada alcantarilla.

En relación a este punto, la construcción entre 1586 y 1592 de la Puerta Nueva de Triana supuso la culminación de la operación iniciada en 1560 por el asistente Francisco Chacón y el maestro mayor de la ciudad Hernán Ruiz II, y continuada por Francisco de Zapata, conde de Barajas, y los arquitectos Benvenuto Tortello y Asensio de Maeda, quienes transformaron las viejas puertas islámicas, que habían perdido su función defensiva, en nuevos accesos dotados de un componente monumental y estético del que aquellas carecían, en cuanto que se erigieron como arcos de triunfo que exaltaban el poder de una ciudad convertida en capital del orbe, a la vez que contribuían a eliminar los vestigios de su pasado islámico y se convertían en elementos de ordenación urbanística (Jiménez Maqueda 1999).

Por último, también hemos sido capaces de detectar arqueológicamente la gran reforma urbanística proyectada en 1859 por Balbino Marrón y que consistió en la alineación de la Cestería, típica operación de decimonónica de ensanche, inmersa en una concepción burguesa de la ciudad que en apenas diez años habría de acabar con la cerca y sus puertas. 


\section{BIBLIOGRAFÍA.}

ALBARDONEDO, A. J. (1992): "Documentos sobre la construcción de la Puerta Nueva de Triana", Laboratorio de Arte 5: 309-323.

AMORES, F. y CHISVERT, N. (1993): "Tipología de la cerámica común bajomedieval y moderna sevillana (ss. XV-XVIII): I. La loza quebrada de relleno de bóvedas", Spal 2: 269-325.

BLANCO, A. (1972): "La Sevilla romana. Colonia Iulia Romula Hispalis", en Historia del urbanismo sevillano. Sevilla.

- (1979): Historia de Sevilla I (1). La ciudad antigua. Sevilla.

CAMPOS, J. M. (1993): "La estructura urbana de la Colonia Iulia Romula Hispalis en época imperial", Anales de Arqueología Cordobesa 4: 181-219.

COLLANTES DE TERÁN DELORME, F. (1972): Inventario de los Papeles del Mayordomazgo del siglo XV (1401-1416). Sevilla.

-(1977): Contribución al estudio de la topografía sevillana en la antigüedad y en la edad media. Sevilla. COLLANTES DE TERÁN SÁNCHEZ, A. (1977): Sevilla en la baja Edad Media. La ciudady sus hombres. Sevilla.

DEAGAN, K. (1987): Artifacts of the Spanish Colonies of Florida and the Caribbean, 1500-1800. Washington.

GOGGIN, J. (1968): Spanish Majolica in the New World. Types of the Sixteenth to Eighteenth centuries. Yale.

GONZÁLEZ DE LEÓN, F. (1839): Noticia histórica del origen de las calles de esta M.N. M.L. y M.H. Ciudad de Sevilla. Sevilla.

HUARTE, R. y SOMÉ, P. (1995): "La cerámica contemporánea en el Cuartel del Carmen (Sevilla)", Spal 4: 229-247.

IBN SAHIB AL-SALA (1969): Al-Mann bil-Imama. Valencia.

JIMÉNEZ MAQUEDA, D. (1999): "Las puertas de Sevilla. Una aproximación histórico-arqueológica", Cuadernos de la Alhambra, 35: 149-159.

JIMÉNEZ MAQUEDA, D. y MOSULÉN, G. (1997): Informe de la intervención arqueológica de urgencia en las calles Reyes Católicos $n^{\circ} 3$ y Almansa $n^{\circ} 6$ (Sevilla) (inédito). Sevilla.

-(1998): Informe de la intervención arqueológica de urgencia en la calle Almansa ${ }^{\circ} 5$ (Sevilla) (inédito). Sevilla.

JIMÉNEZ MARTÍN, A. (1981): “Análisis formal y desarrollo histórico de la Sevilla medieval”, en La arquitectura de nuestra ciudad. Sevilla.

LAFUENTE, P. (1997): "Cerámica medieval”, en El Real Monasterio de San Clemente. Una propuesta arqueológica. Sevilla: 107-129.

LLUBIA, L. M. (1967): Cerámica medieval española. Barcelona.

MAL LARA, J. de (1570): Recebimiento que hizo la muy noble y muy leal Ciudad de Sevilla, a la C.R.M. del Rey D. Philipe N.S. Sevilla.

MARÍN, L. (1980): Sevilla: centro urbano y barriadas. Sevilla.

MARTÍNEZ, B. (1982): La loza dorada. Madrid.

ORTÍZ DE ZÚÑIGA, D. (1677): Annales eclesiásticos y seculares de la muy noble y muy leal ciudad de Sevilla, metrópoli de la Andaluzia, que contienen sus mas principales memorias. Sevilla.

PLEGUEZUELO, A. (1989): Azulejo sevillano. Sevilla.

PLEGUEZUELO, A. y LAFUENTE, P. (1995): “Cerámicas de Andalucía Occidental”, en Spanish Medieval Ceramics in Spain and the British Isles. Oxford: 217-244. 
PLEGUEZUELO, A. et alii (1997): “Cerámicas de la edad moderna (1450-1632)”, en El Real Monasterio de San Clemente. Una propuesta arqueológica. Sevilla: 130-157.

QUIRÓS, C. A. (1999): "La intervención arqueológica de urgencia de la calle Pastor y Landero, 35 y Galera 26-28. Sevilla" AAA 1994/IV. Sevilla: 517-521.

SUÁREZ, J. M. (1986): Arquitectura y urbanismo en la Sevilla del siglo XIX. Sevilla.

VALENCIA, R. (1988): Sevilla musulmana hasta la caída del Califato: Contribución a su estudio. Madrid.

VALOR, M. (1991): La arquitectura militar y palatina en la Sevilla musulmana. Sevilla. 


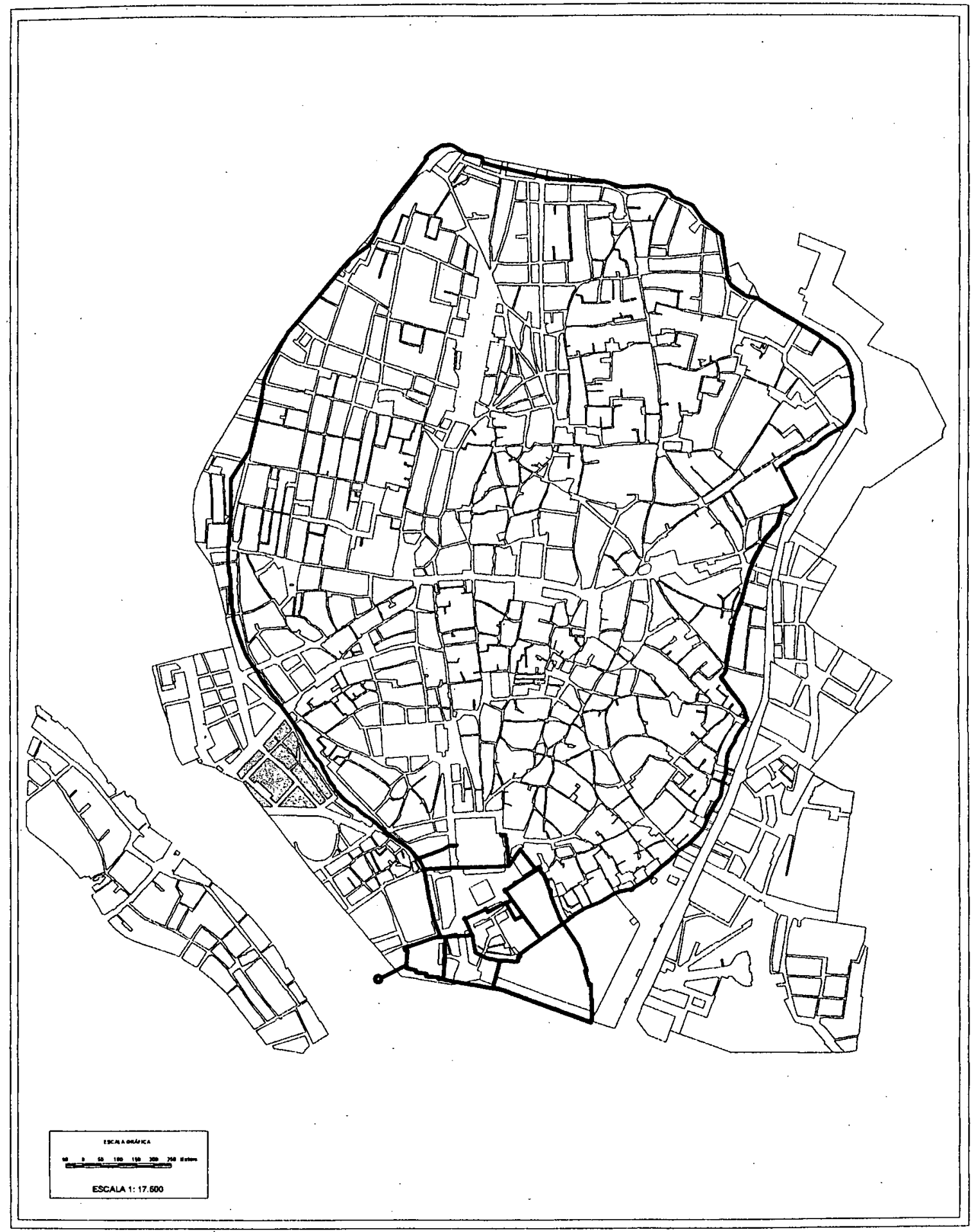

Fig. 1: Emplazamiento del arrabal de la Cestería. 


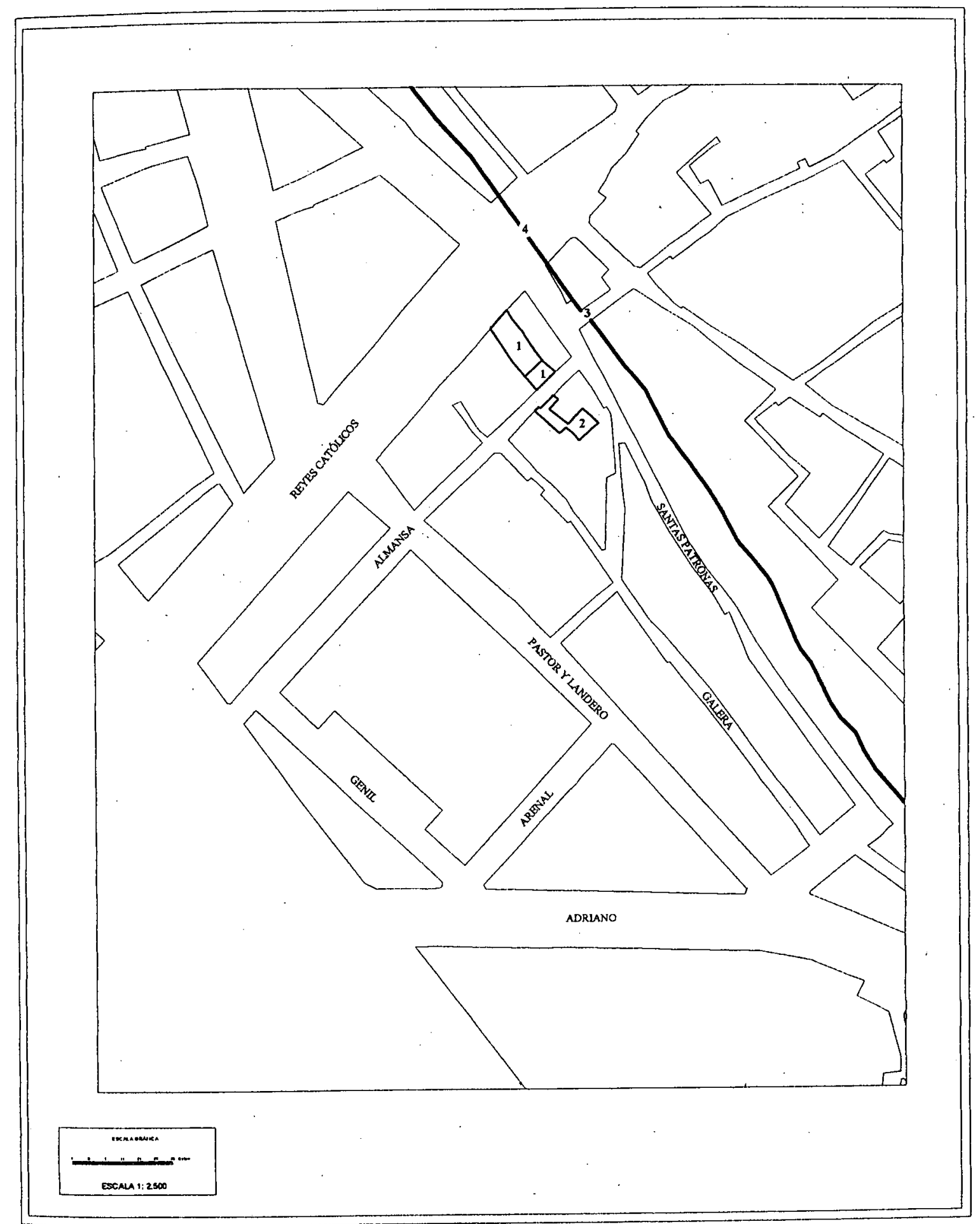

Fig. 2: Plano de la Cestería: (1) Reyes Católicos 3/Almansa 6; (2) Almansa 5; (3) Puerta Antigua de Triana (siglo XII-1592); (4) Puerta Nueva de Triana (1592-1869). 


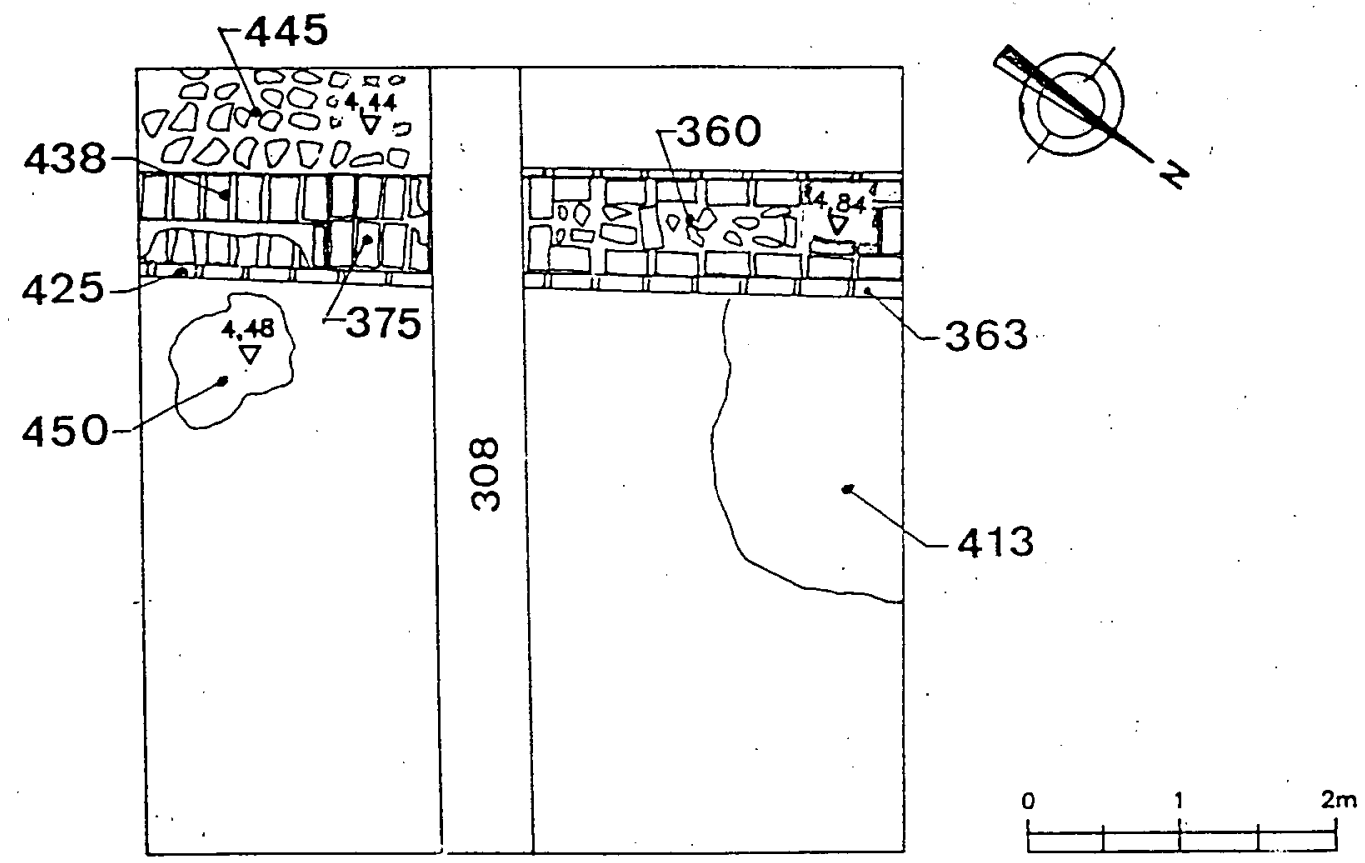

Fig. 3: Estructuras bajomedievales en la U.I. 2 de RC 3/Al 6.
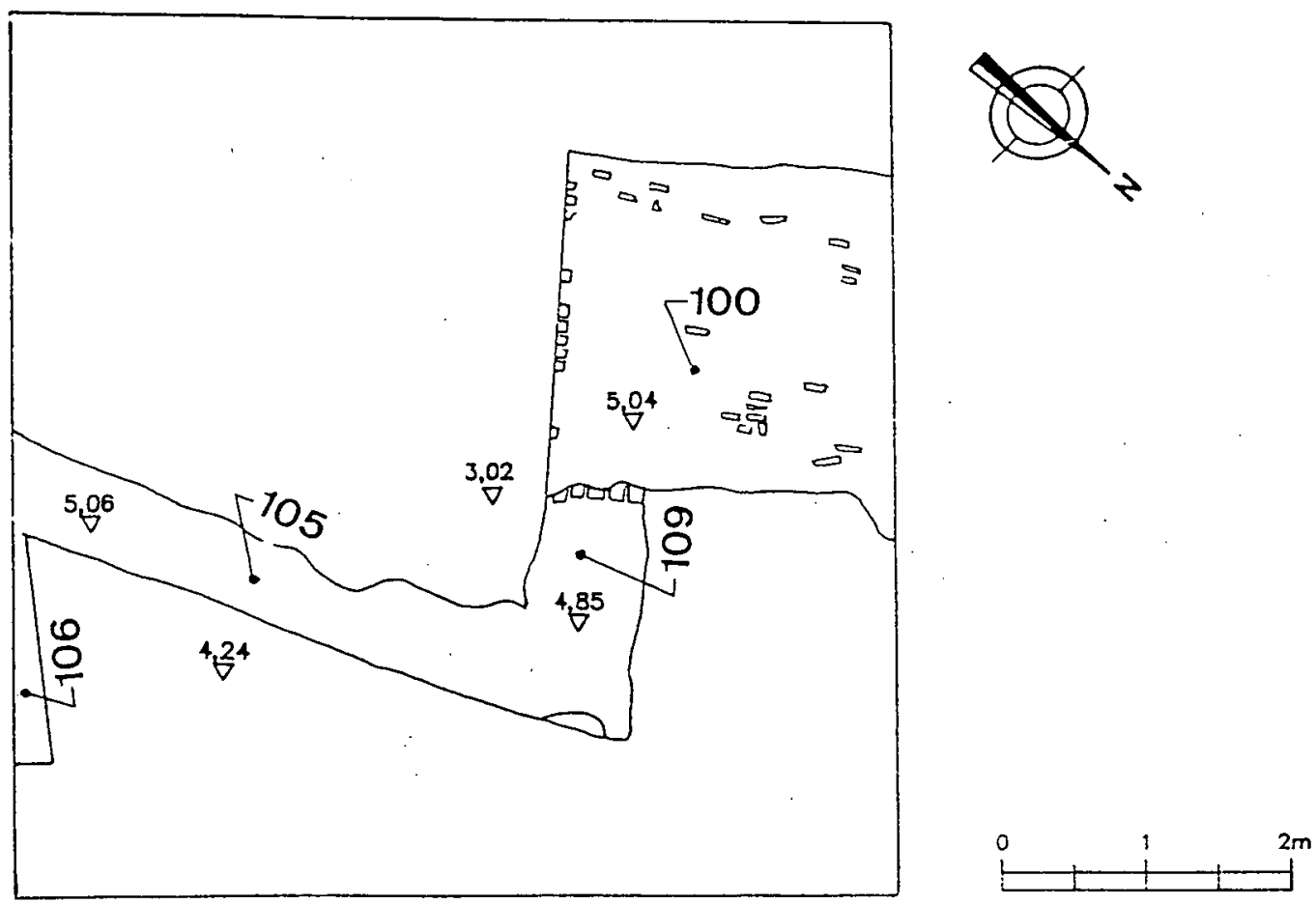

Fig. 4: Estructuras de la 1/2 del siglo XVI en la U.I. 1 de RC 3/AI 6. 

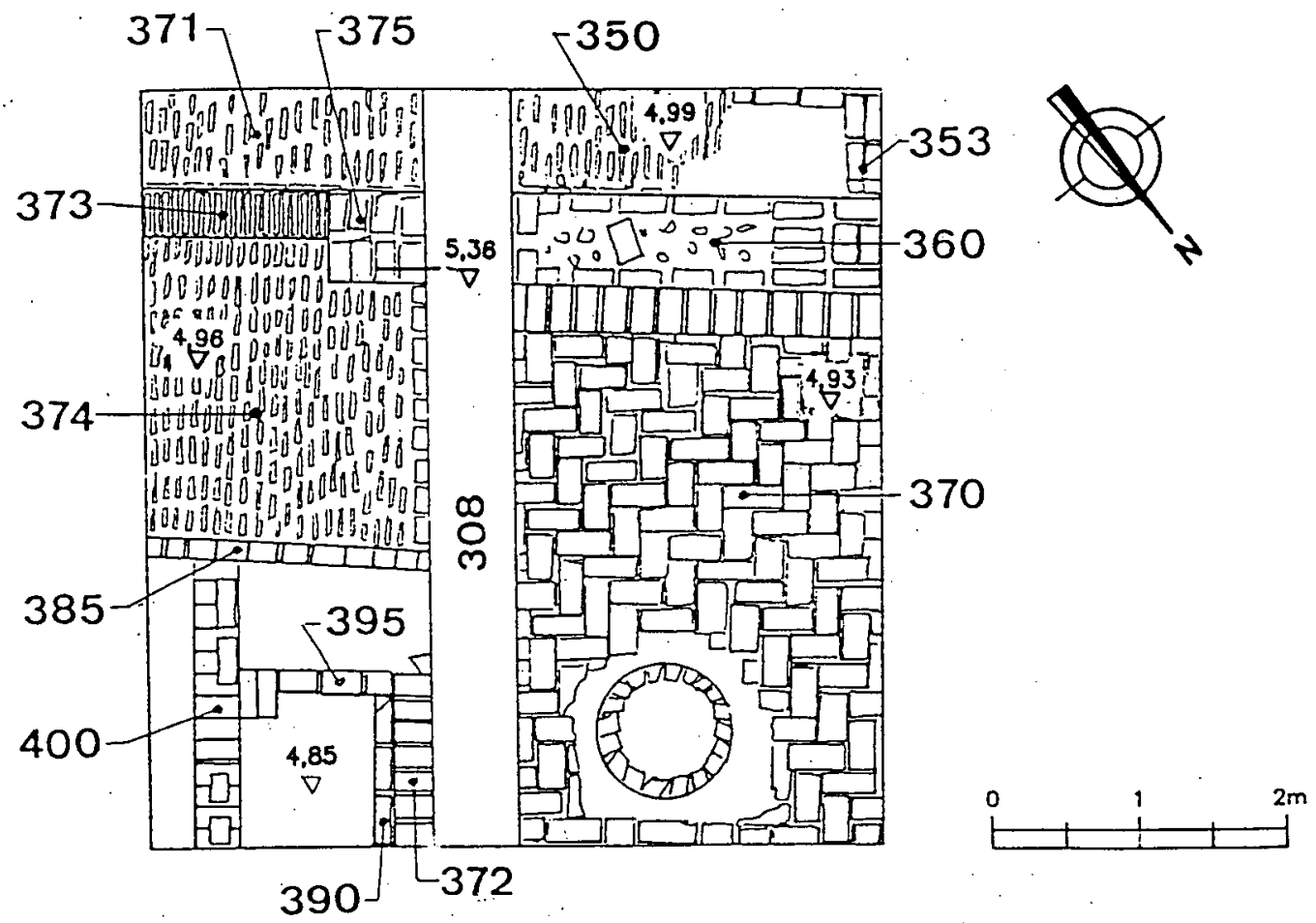

Fig. 5: Estructuras de la 1/2 del siglo XVI en la U.I. 2 de RC 3/Al 6.
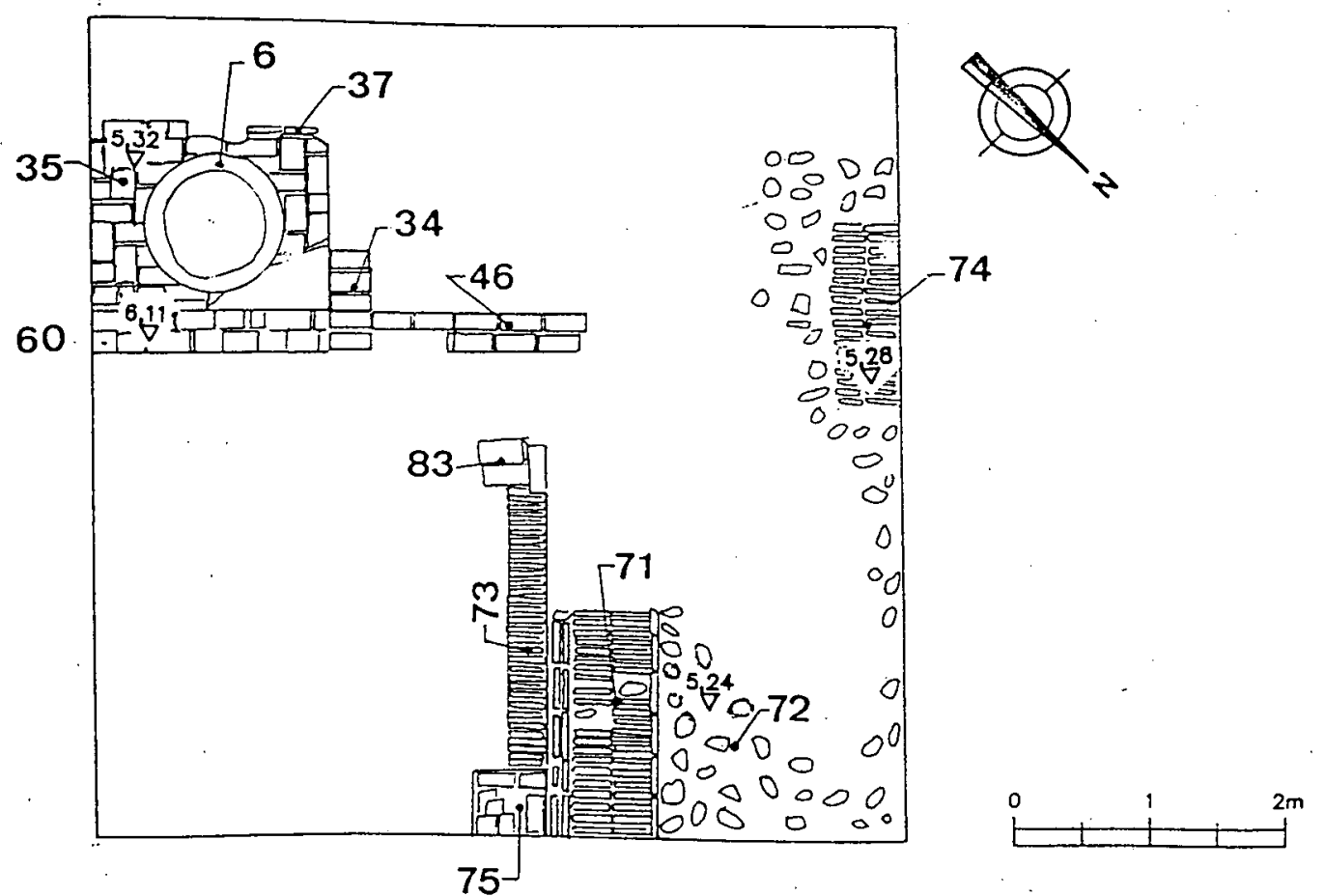

Fig. 6: Estructuras del 1/3 del siglo XVII en la U.I. 1 de RC 3/Al 6. 


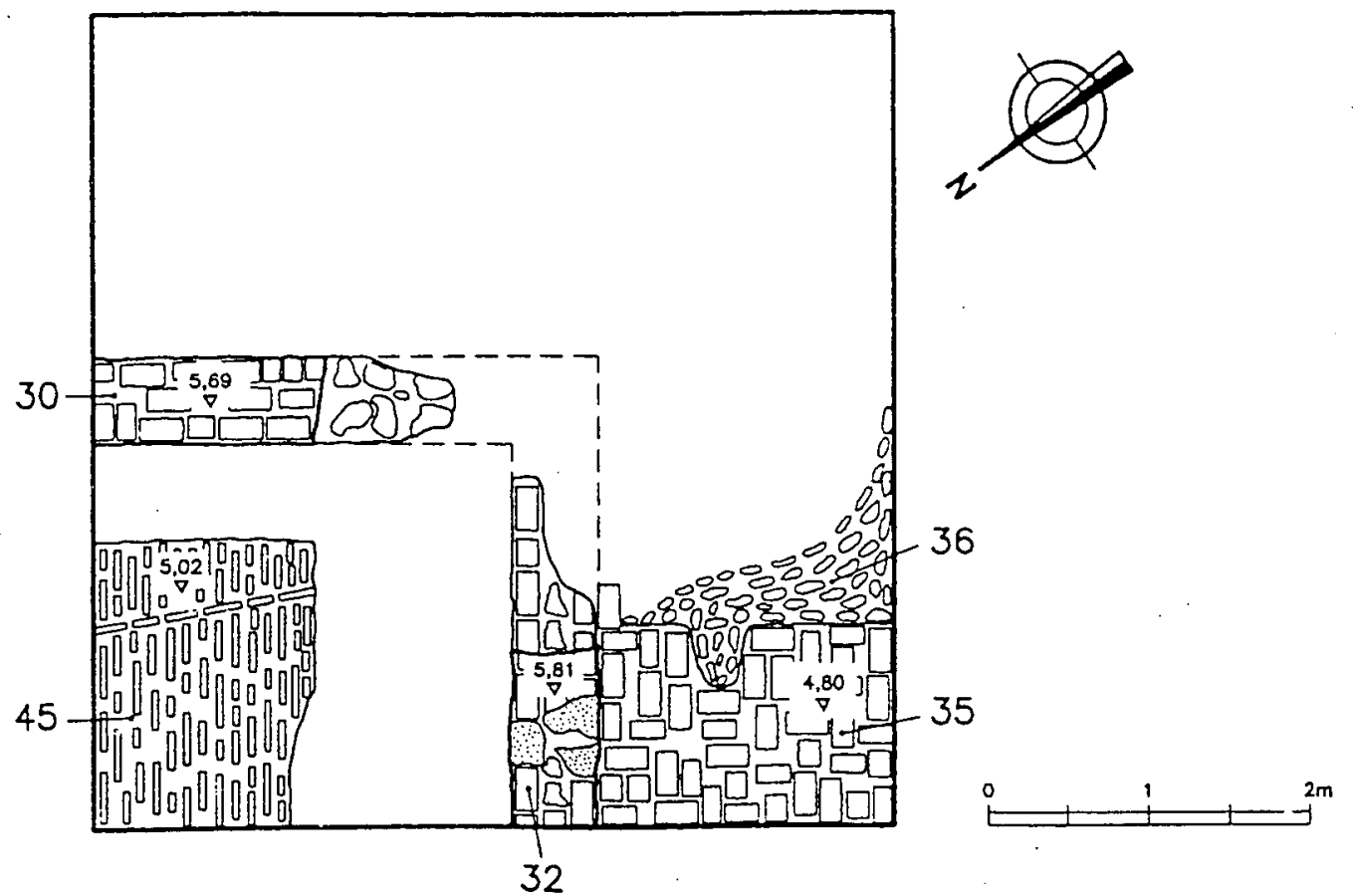

Fig. 7: Estructuras del 1/3 del siglo XVII en Al 5.
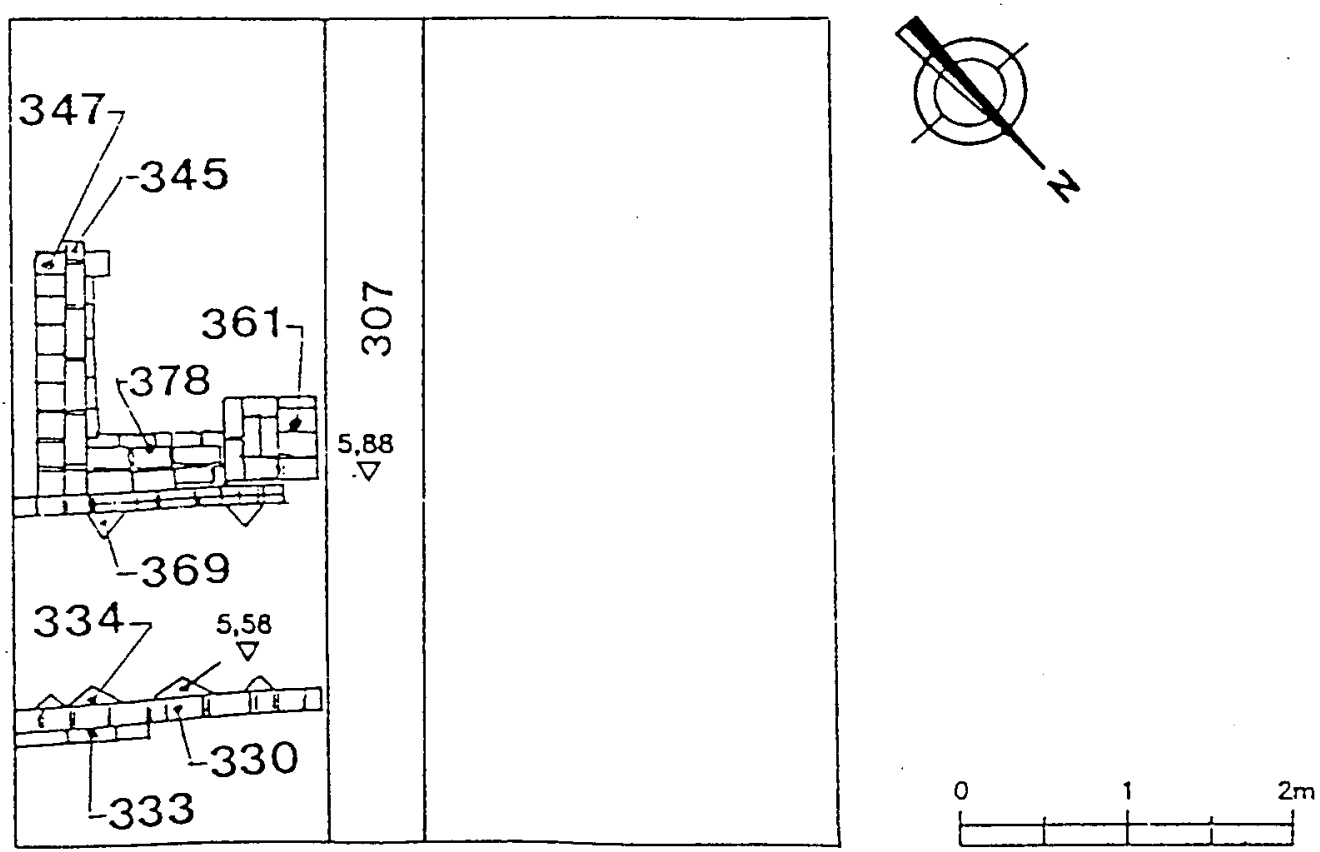

Fig. 8: Estructuras de los siglos XVII-XVIII en la U.I. 2 de RC 3/Al 6. 


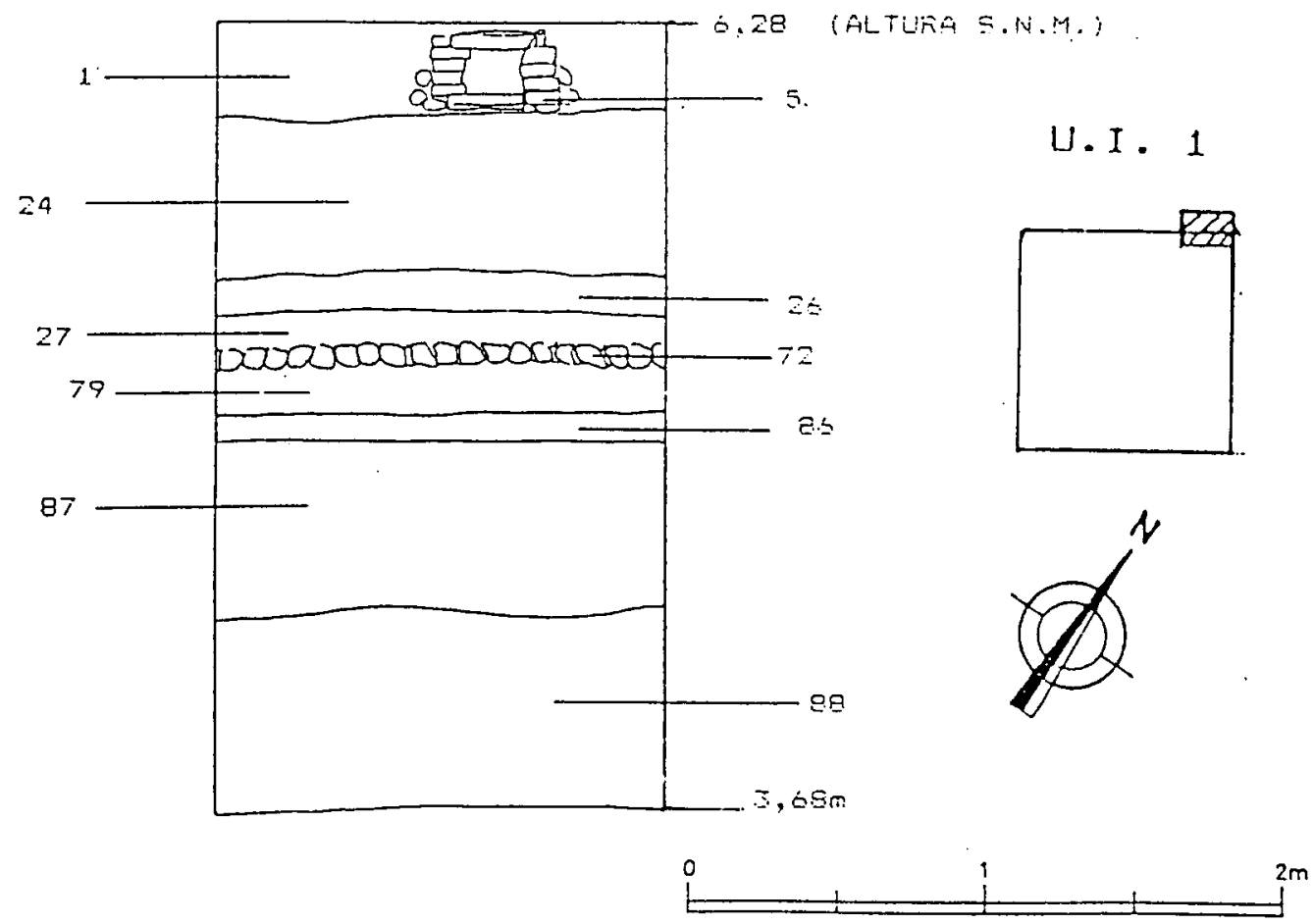

Fig. 9: Perfil NO de la U.I. 1 de RC 3/Al 6.

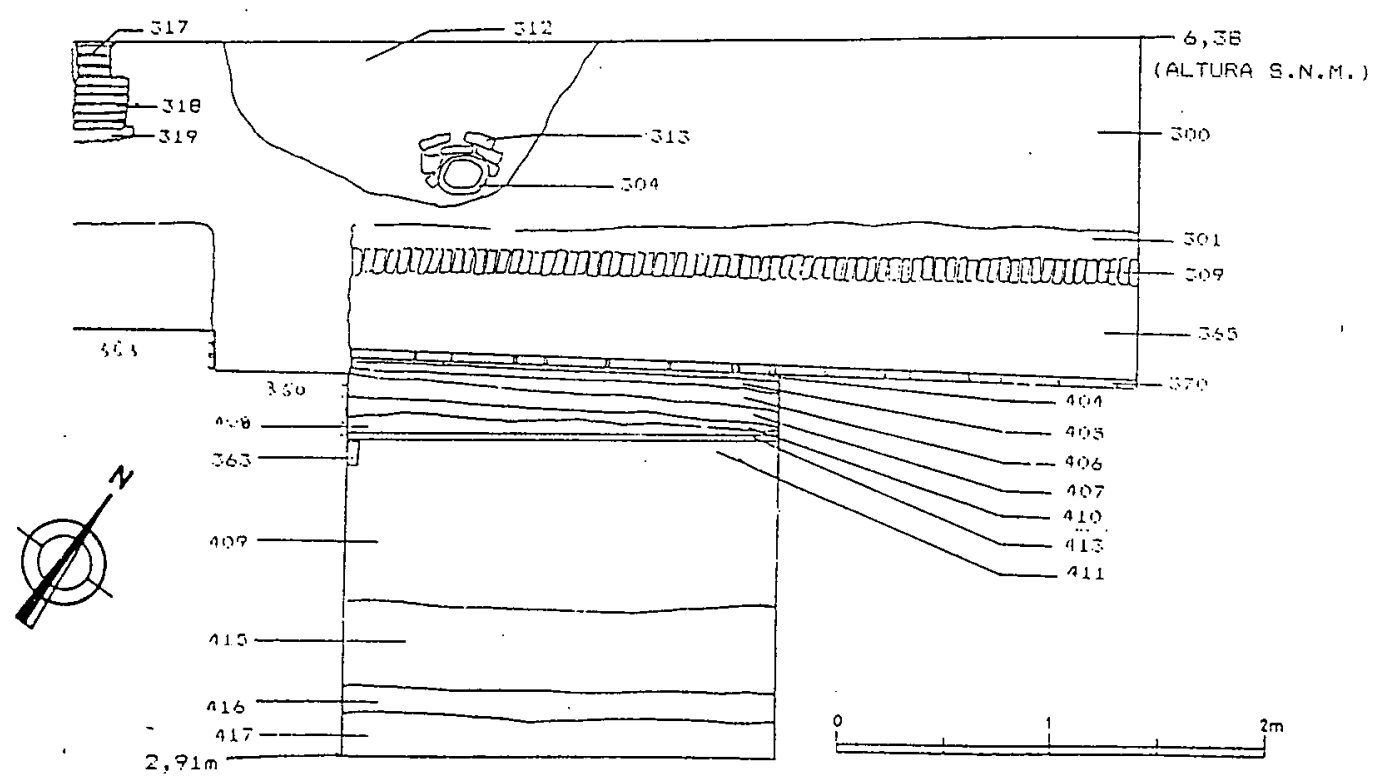

Fig. 10: Perfil NO de la U.I. 2 de RC 3/Al 6. 


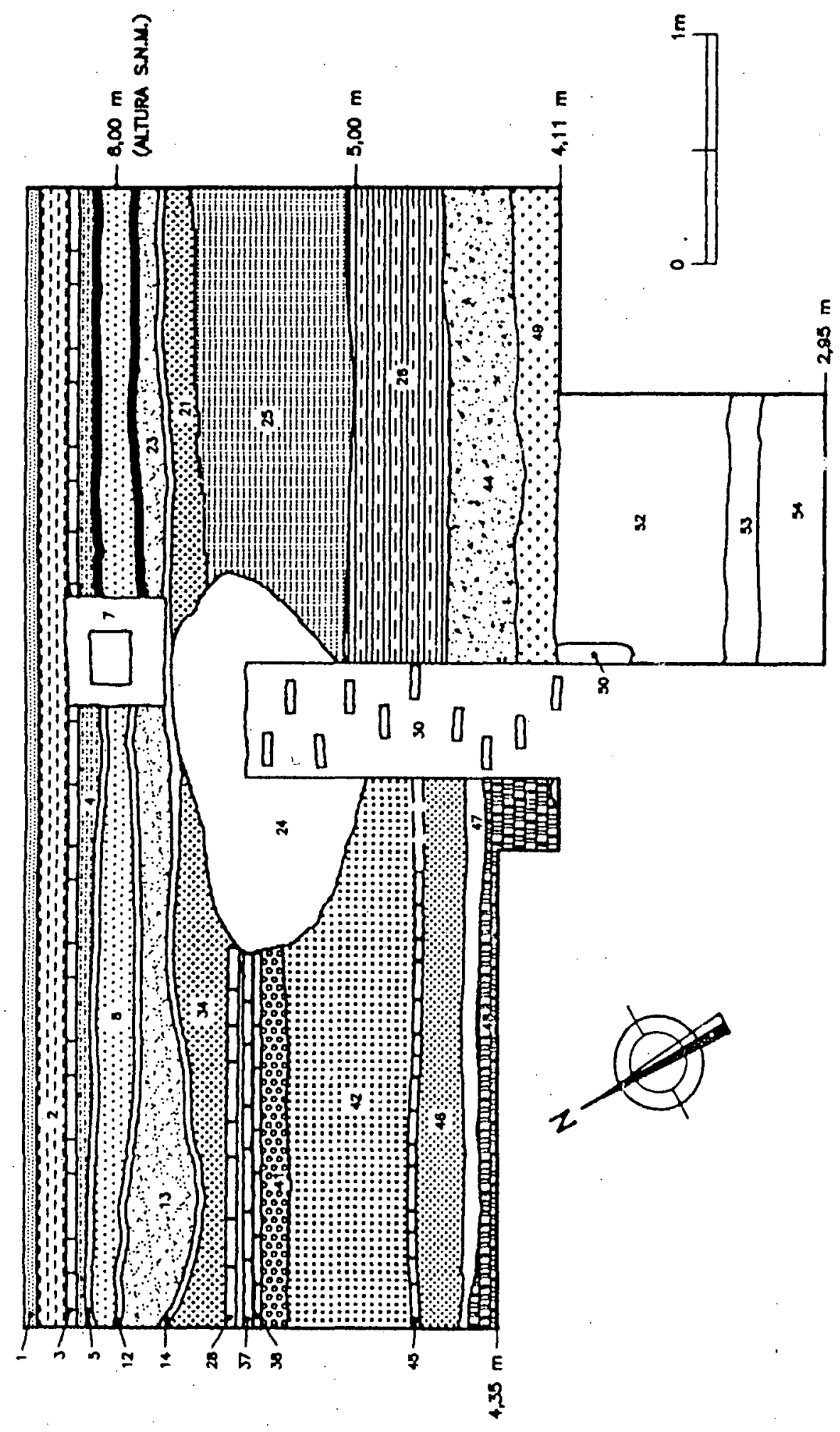

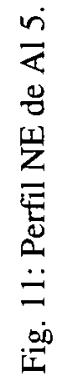




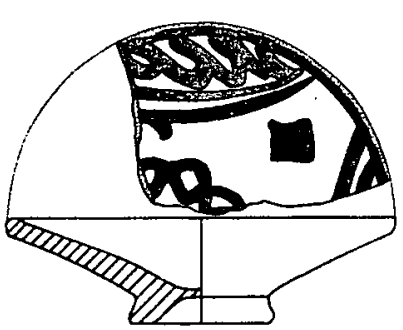

163

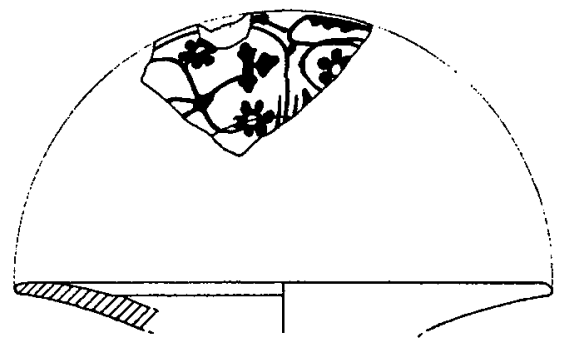

127
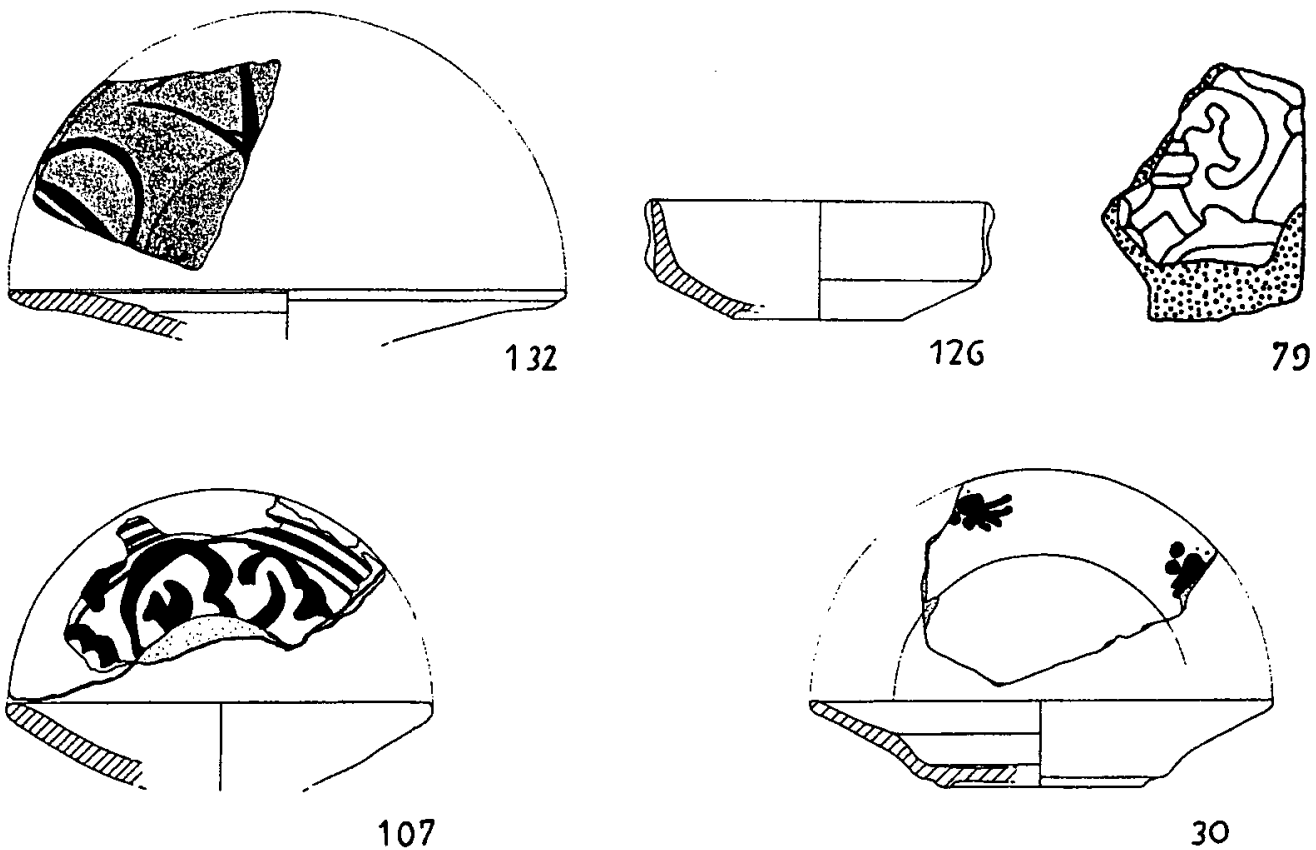

79

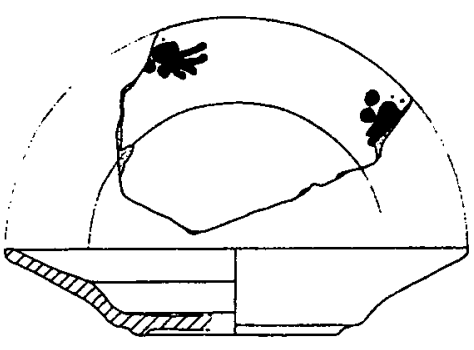

30

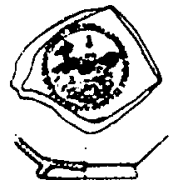

32

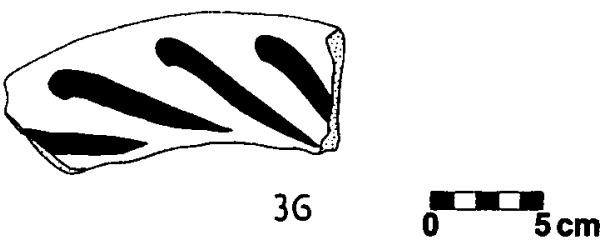

Fig. 12: Material cerámico de RC 3/Al 6. 


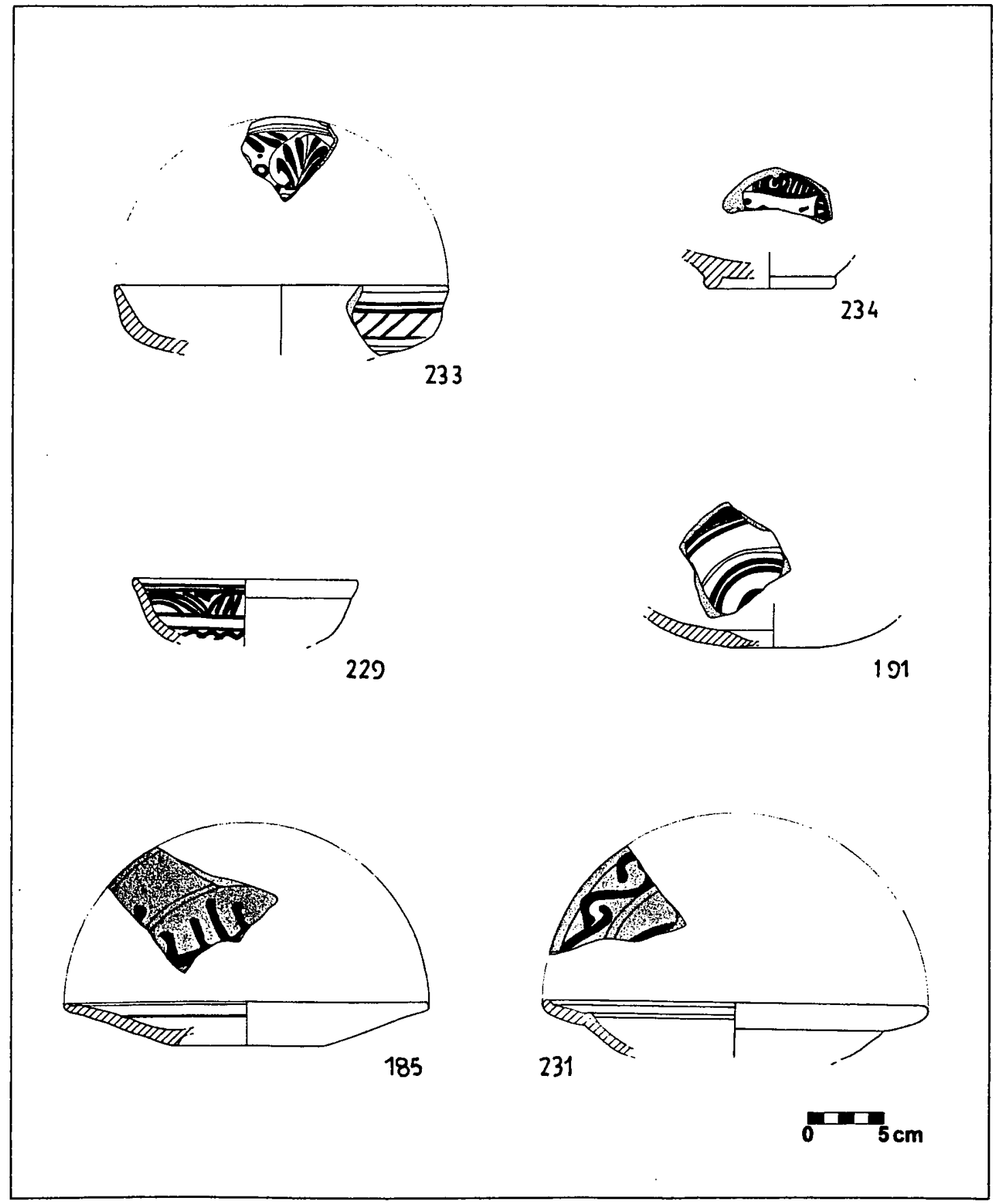

Fig. 13: Material cerámico de $\mathrm{Al} 5$. 


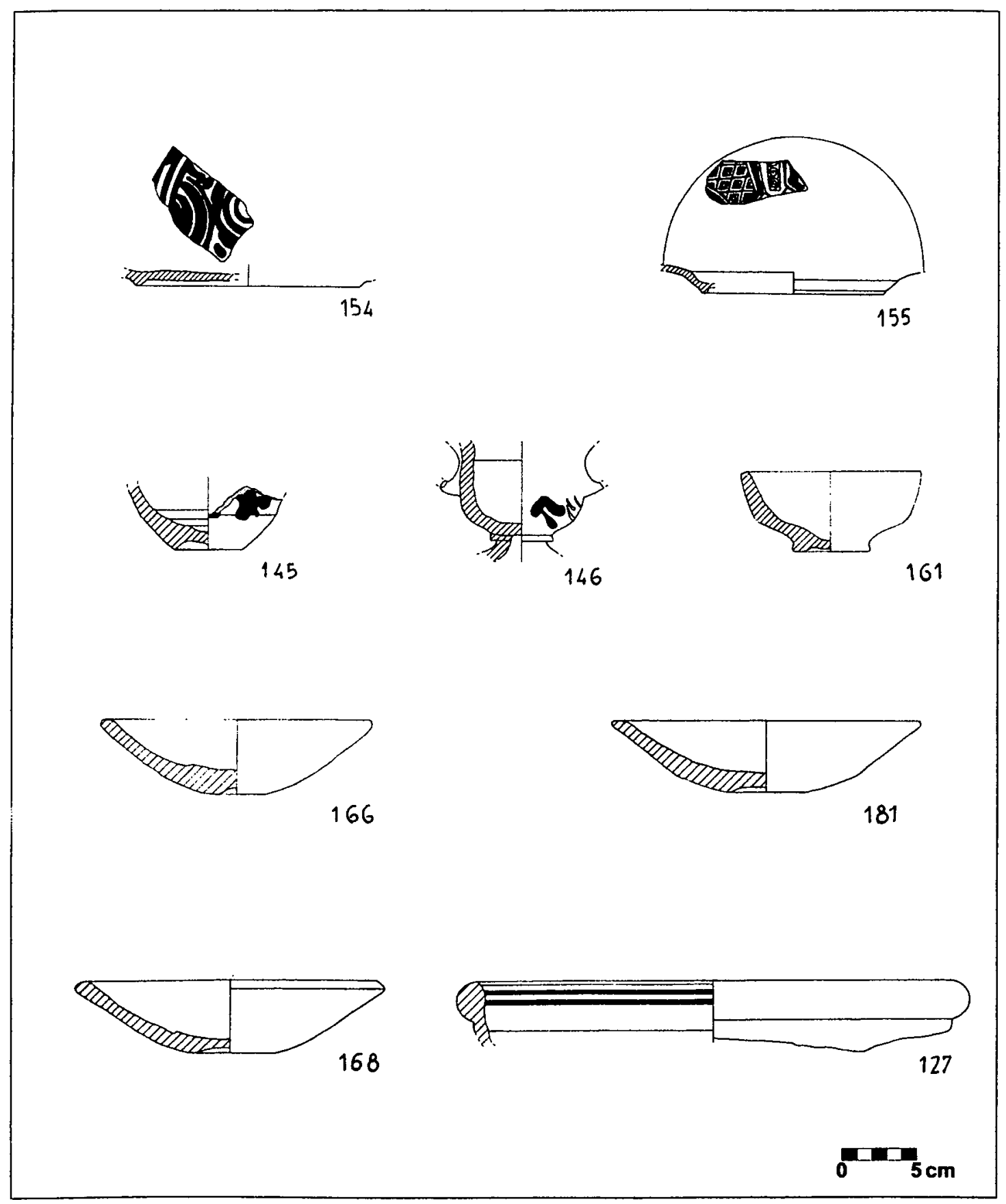

Fig. 14: Material cerámico de $\mathrm{Al} 5$. 


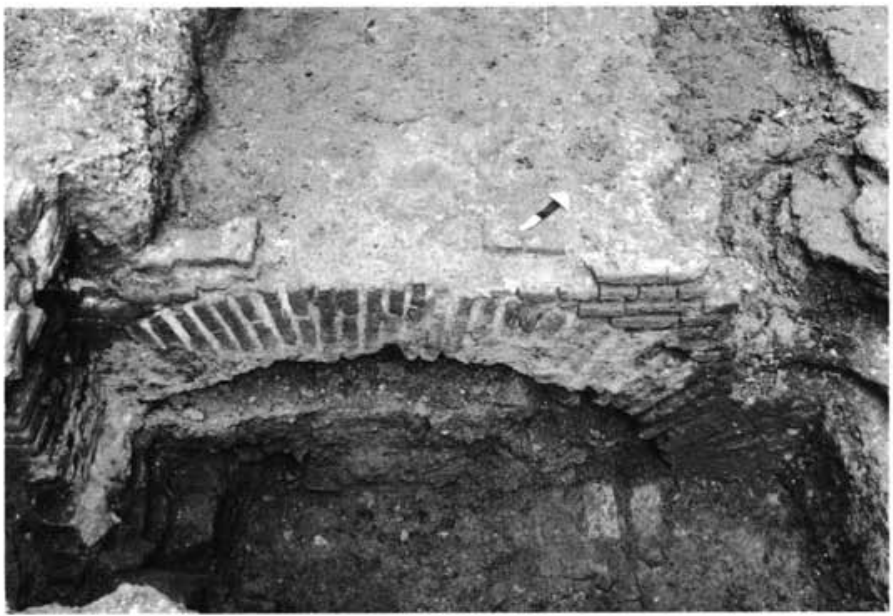

Lám. I: Alcantarilla de la Puerta Antigua de Triana en la U.I. I de RC 3/Al 6.

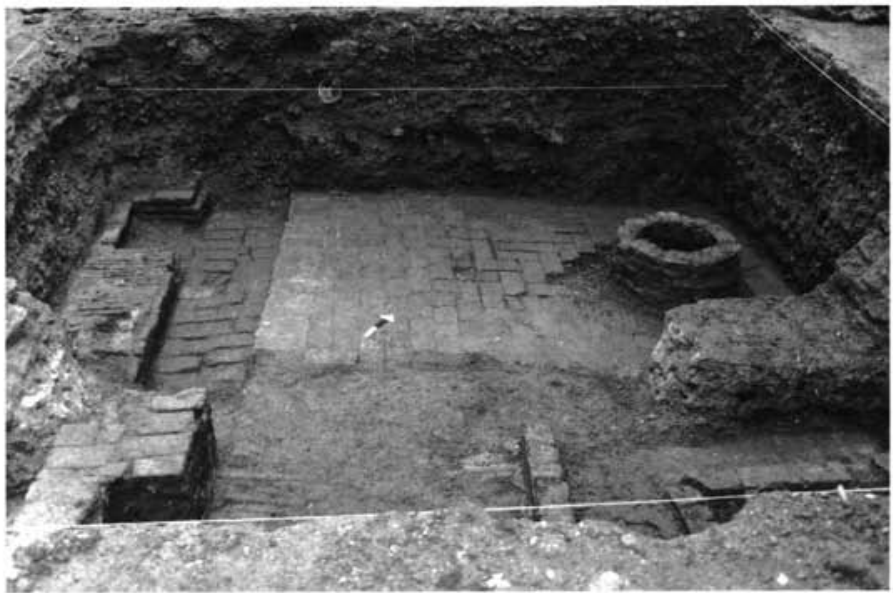

Lám. II: Estructuras de la 1/2 del siglo XVI en la U.I. 2 de RC 3/Al 6. 


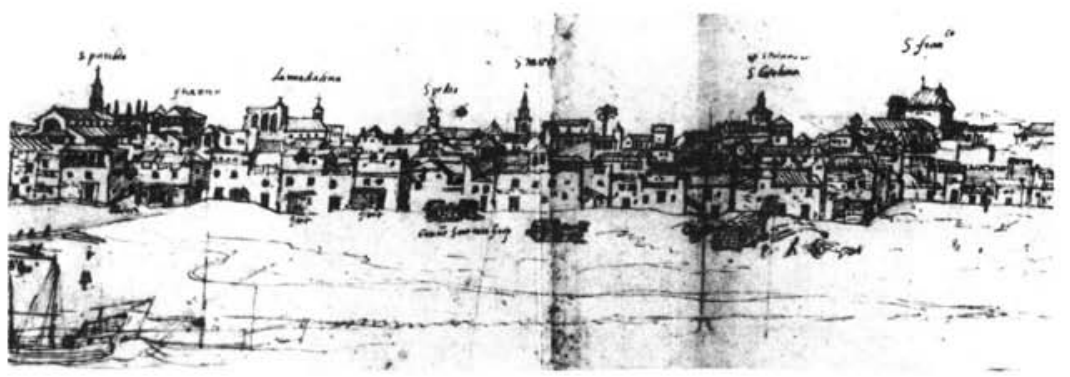

Lám. III: Vista de Sevilla desde Triana. Anton van den Wyngaerde, 1567. Londres, Victoria and Albert Museum.

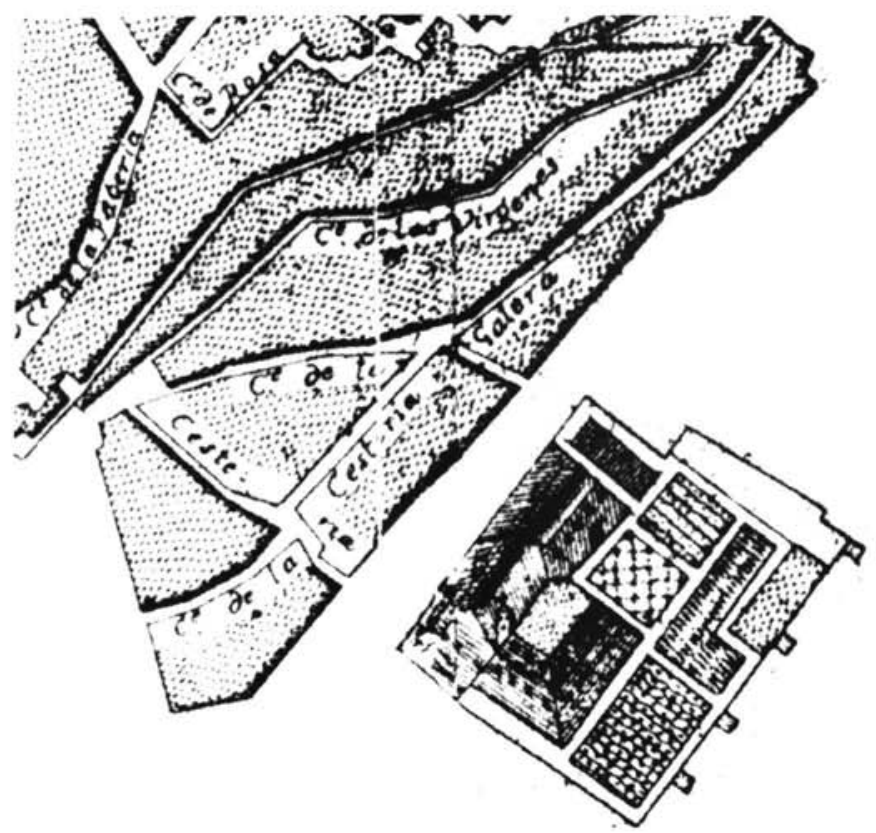

Lám. IV: Plano del Asistente Pablo de Olavide elaborado por Francisco Manuel Coelho, 1771. Sevilla, Archivo Municipal. 